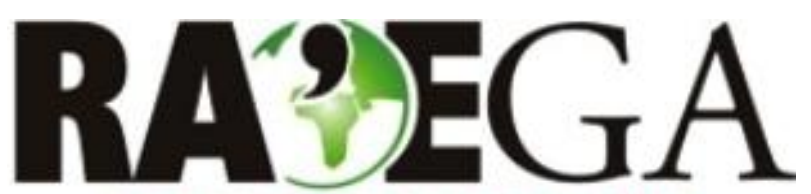

O ESPAÇO GEOGRÁFICO EM ANÁLISE

\title{
OS RURAIS E A CIDADE: A MOBILIDADE SOCIOESPACIAL DOS HABITANTES DO CAMPO EM PEQUENOS MUNICÍPIOS DE ECONOMIA AGRÍCOLA
}

\section{THE RURALS AND THE CITY: THE SOCIO-SPATIAL MOBILITY OF THE COUNTRYSIDE INHABITANTS IN SMALL COUNTIES OF AGRICULTURAL ECONOMY}

\author{
Nayhara Freitas Martins Gomes ${ }^{1}$, Ana Louise Carvalho Fiúza ${ }^{2}$, Neide Maria Almeida Pinto ${ }^{3}$, Paula Cristina \\ Almeida Cadima Remoaldo ${ }^{4}$
}

\section{RESUMO}

Este artigo trata da mobilidade socioespacial dos rurais em pequenos municípios situados na Microrregião de Viçosa, região agrícola de forte presença do café. A mobilidade dos habitantes do campo, nestes pequenos municípios, tem se intensificado mediante a maior facilidade de acesso aos meios de transporte e comunicação que viabilizam a aproximação corriqueira com a cidade. Esta interação permite aos rurais estabelecerem múltiplas espacialidades, resultantes dos deslocamentos que realizam aos seus espaços de afinidade. $O$ presente artigo objetivou compreender e identificar os espaços frequentados e ocupados pelos rurais na cidade, por compreender que os mesmos são reveladores do vínculo de pertencimento que estabelecem com à cidade. $O$ estudo foi realizado no pequeno município de Araponga, situado na Mesorregião da Zona da Mata mineira, o qual tem na cafeicultura a base de sua economia. Realizou-se uma pesquisa cross-sectional com uma amostra representativa da população, composta por 94 habitantes da zona rural. Buscou-se identificar na pesquisa quais eram os espaços mais frequentados pelos rurais na cidade. Os resultados revelaram vieses de gênero na construção das espacialidades citadinas, as quais se configuraram como predominantemente locais e denotaram o sentimento de pertencimento dos rurais à vida da cidade.

Palavras-chave: campo; cidade; rurais; espacialidades.

\section{ABSTRACT}

This article talks about the socio-spatial mobility of the rurals in small counties located in the micro region of Viçosa, agricultural region of strong presence of coffee. The mobility of the countryside inhabitants in these small counties has been intensified due to the greater ease of access the means of transportation and communication that enable the everyday approach with the city. This interaction allows the rurals to estabilish multiple spatialities, resulting from the displacements that they make to their afinity spaces. The present article aimed to understand and identigy the spaces attended and occupied by the rurals in the city, by understanding that the same are developers of the belonging bonds they estabilish with the city. This study was realized in the small county of Araponga, located in the meso region of Forest Zone of Minas Gerais State, which has in the coffee crops the base of its economy. A cross-sectional survey was conducted with a representative sample of population, composed by 94 inhabitants of the countryside. We sought to identify in the rerearch whuch were the most attended spaces by the rurals in the city. The results revealed gender biases in the construction of city spatialities, in which configured as predominantly local and denoted the sense of belonging of the rurals to the life of the city.

Key-words: countryside; city; rurals; spatialities.

Recebido em: 16/01/2017

Aceito em: 04/09/2017

\footnotetext{
${ }^{1}$ Universidade Federal de Minas Gerais,Belo Horizonte/MG, email: nayhara_martins@yahoo.com.br,

${ }^{2}$ Universidade Federal de Viçosa, Viçosa/MG, email: louisefiuza@ufv.br

${ }^{3}$ Universidade Federal de Viçosa, Viçosa/MG, email: nalmeida@ufv.br

${ }^{4}$ Universidade do Minho, Minho/Portugal, email: premoaldo@geografia.uminho.pt
} 


\section{OS RURAIS E A CIDADE: A MOBILIDADE SOCIOESPACIAL DOS HABITANTES DO CAMPO EM PEQUENOS MUNICÍPIOS DE ECONOMIA AGRÍCOLA}

\section{INTRODUÇÃO}

O presente artigo objetiva analisar a mobilidade socioespacial dos rurais mediante os intercâmbios estabelecidos em suas relações costumeiras com a cidade, em um pequeno município ${ }^{5}$ de economia cafeeira, situado na Zona da Mata mineira. Tal município, como outros pequenos municípios que compõem a Microrregião de Viçosa possuem densidade demográfica inferior a 50 habitantes por $\mathrm{km}^{2} \mathrm{e}$ população menor do que 10 mil habitantes. A população residente em Araponga, tal como a metade dos outros municípios da Microrregião de Viçosa encontra-se distribuída majoritariamente na zona rural 15.122 habitantes) e outros 3.042 na cidade. Este fato reforça a importância de se compreender a relação dos rurais com a cidade em pequenos e médios municípios ao seu entorno. A compreensão destes movimentos rotineiros, relativos ao deslocamento da população rural a fim de trabalhar, estudar, buscar a prestação de serviços, comprar bens pessoais e de uso domésticos, dentre tantos outros fins, permite compreender as funções que os pequenos municípios de economia agrícola cumprem na vida das pessoas que permanecem o campo.

Entre as décadas de 1960 e 1990 a população rural migrou em grande intensidade para os grandes centros urbanos em função de reestruturações produtivas decorrentes da modernização no espaço rural, além de ofertas locacionais para os trabalhadores migrantes (MATOS \& BAENINGER, 2004, p.11) que buscavam nas cidades alternativas para melhores condições de vida. Entretanto, o ritmo de esvaziamento nos pequenos municípios desacelera a partir da década de 1990, embora poucos estudos tem se interessado sobre o modo de vida rural da população que hoje vive no campo destes pequenos municípios. Este artigo procura analisar a relação dos rurais com a cidade, sob o prisma das espacialidades citadinas

\footnotetext{
5 Cumpre destacar que este trabalho adota o termo "pequenos municípios" por se referir ao município em sua totalidade, não apenas fazendo menção ao espaço citadino.
}

por eles construída ao se deslocarem para satisfazer as suas necessidades e desejos.

A circulação e a mobilidade de pessoas, bens, símbolos e mercadorias na cidade dão-se de forma diferenciada, de acordo com os fatores econômicos, políticos e culturais (PEREIRA, 2007, p.55-56). O espaço urbano é produzido, reproduzido e apropriado de forma segmentada socioespacialmente. Vasconcelos (2001, p.179) observa que tanto as pessoas de menor poder de consumo quanto às de maior, se apropriam do espaço citadino de formas variadas, se movendo de maneira segmentada pela a cidade. Tanto uns como outros desconhecem muitas parcelas de seu território e não o apreendem em toda a sua totalidade. Mas e quanto às espacialidades citadinas dos rurais como são constituídas? As espacialidades construídas revelam, também, acessibilidades marcadas por especificidades em relação à cidade? Estariam às espacialidades citadinas dos rurais demarcadas apenas pela lógica econômica, ou os modos de vida dos rurais e dos citadinos expressariam nuances específicas?

Os deslocamentos cotidianos realizados pelos rurais entre o campo e a cidade permite compreender a forma como vem se efetivando a mudança nos modos de vida das pessoas que residem nos pequenos municípios, com até 20.000 habitantes e densidade menor que 80 $\mathrm{hab} / \mathrm{Km}^{2}$, os quais representam mais de $80 \%$ dos municípios brasileiros (VEIGA, 2004, p.80). Examinar o deslocamento campo-cidade realizado de forma rotineira pelos rurais é relevante, ainda, por permitir analisar os sincronismos e dissonâncias entre o modo de vida rural e urbano.

Assim, a temática deste trabalho voltada para o estudo da "mobilidade socioespacial e da construção de espacialidades e suas influências no modo de vida dos habitantes do campo" pode vir a contribuir para ampliar a compreensão em torno do fenômeno da mobilidade entre pessoas que vão e vêm entre o campo e as pequenas cidades brasileiras. Compreender as motivações que levam os rurais a deslocarem-se 


\section{OS RURAIS E A CIDADE: A MOBILIDADE SOCIOESPACIAL DOS HABITANTES DO CAMPO EM PEQUENOS MUNICÍPIOS DE ECONOMIA AGRÍCOLA}

rotineiramente para fora de seu espaço de origem pode, ainda, permitir perceber as mudanças em seus modos de vidas e nas suas atividades cotidianas, considerando, inclusive, especificidade de gênero e geração. Buscamos, enfim, com este estudo ampliar a compreensão acerca do fenômeno da mobilidade socioespacial sob o prisma do contato entre modos de vida rurais e urbanos.

\section{MATERIAIS E MÉTODOS}

A investigação realizada teve um caráter crosssectional $^{6}$, com a aplicação de questionários uma única vez para cada respondente. A pesquisa teve um caráter descritivo voltado para apresentar as diversas características relativas à realidade investigada e, também, explicativa por ter buscado evidenciar os fatores implicados da construção de espacialidades em pequenos municípios de economia agrícola (GIL, 2010, p.26). Empregou-se uma combinação de desenhos de pesquisa qualitativos e quantitativos para compreender este fenômeno. Conforme Reichardt e Cook (1979, p.14), a abordagem qualitativa busca descrever significados que são socialmente construídos e que assumem uma dimensão subjetiva. Enquanto a abordagem quantitativa procura descrever os significados da realidade estudada de forma objetiva permitindo uma análise focalizada e pontual dos dados.

A coleta de dados foi realizada com a população rural do pequeno município de Araponga, pertencente à microrregião de Viçosa, Minas Gerais. Este local foi escolhido em virtude do município ter uma população inferior a 20.000 habitantes e ter uma economia agrícola. Adotouse neste estudo uma amostra probabilística e representativa da população. Os indivíduos que a constituíram foram escolhidos por um processo em que todos os membros da população tinham a mesma probabilidade de fazer parte da amostra. Assim, a amostra representativa da

\footnotetext{
${ }^{6}$ A pesquisa realizada em uma abordagem crosssectional ou transversal pode ser feita analisando-se o fenômeno de interesse medindo-se cada variável apenas uma vez, ou seja, num único instante de tempo.
}

população permitiu que os resultados fossem confiáveis para avaliar as características da população. Em uma primeira etapa, para o cálculo da amostra, identificou-se as unidades domiciliares rurais, através da consulta aos dados cadastrais fornecidos pelas Unidades Básicas de Saúde (UBS) da Secretaria de Saúde de Araponga, MG.

A amostra foi composta por 94 indivíduos, sendo definida segundo a fórmula da proporção finita de Bolfarine e Bussab (2005, p.28), assumindo-se o erro de estimativa de $10 \%$ e $95 \%$ como grau de confiança. Os dados primários foram coletados por meio de um Survey com perguntas fechadas e abertas, sendo a unidade de análise o indivíduo, segmentado em faixas etárias e sexo. Adotou-se também, uma metodologia complementar do tipo observação participante realizada durante algumas viagens de ônibus acompanhando os deslocamentos realizados pelos rurais no seu dia a dia. Os dados do Survey foram tabulados e submetidos a análises estatísticas com a ajuda do software SPSS 20.0 (Statistical Package for Social Sciences).

Para a descrição e comparação dos dados partiu-se de uma análise exploratória (EAD) utilizada sob a perspectiva de gênero e de geração. Para tanto dividiu-se os entrevistados em estratos, configurados a partir da faixa estaria na qual o indivíduo se incluía. As faixas etárias criadas seguiram uma lógica voltada para a cultura local, segundo a qual "jovens" seriam os indivíduos que ainda se dedicavam ao estudo e não se casaram, tendo geralmente entre os $15 \mathrm{e}$ os 19 anos; os "jovens adultos" estavam na faixa dos 20 aos 29 anos, já tendo um percentual significativo de casados; na faixa dos 30 aos 39 anos, estavam aqueles indivíduos que possuíam filhos pequenos; na faixa etária dos 40 a 49 anos, aqueles indivíduos que já possuíam filhos adolescentes; na faixa etária dos 50 a 59 anos, aqueles que já possuíam filhos adultos e, na faixa etária acima dos 60 anos, aqueles indivíduos que já possuíam filhos morando fora de casa e que já recebiam ou estão prestes a receber aposentadoria. 


\section{OS RURAIS E A CIDADE: A MOBILIDADE SOCIOESPACIAL DOS HABITANTES DO CAMPO EM PEQUENOS MUNICÍPIOS DE ECONOMIA AGRÍCOLA}

\section{RESULTADOS E DISCUSSÃO}

\subsection{AS ESPACIALIDADES CITADINAS DOS RURAIS EM PEQUENOS MUNICÍPIOS DE ECONOMIA AGRÍCOLA}

O recorte analítico referente à espacialidade nos permite analisar a maneira de produzir os lugares e os usos a eles destinados. Nesta seara, esta investigação concebe as espacialidades citadinas dos habitantes do campo como porções territoriais demarcadas pela sua presença. Os rurais apropriam-se da cidade ao demandá-la, desenvolvendo com ela relações de afinidade e laços de pertencimento, tal como aponta Santos (1997), para quem as espacialidades se desenvolvem a partir da geografização das relações sociais, se constituindo em formas sociais singulares de apropriação e utilização dos recursos em um determinado espaço geográfico. As espacialidades representam mecanismos de apropriação dos recursos disponíveis, gerando relações humanas de produção distintas daquelas vigentes em escala macro e, consequentemente, formas distintas de pensar e agir no e com o mundo (COLUCCI, 2011, p.118). Ao serem conformadas trazem consigo a percepção da mutabilidade, principalmente, no que se refere à interação campo-cidade.

Analisou-se, neste estudo, tanto a espacialidade constituída pelos rurais a partir dos deslocamentos que realizavam costumeiramente dentro dos municípios de pequeno porte em que viviam, como, também, aqueles realizados para os centros urbanos de maior porte, situados até $80 \mathrm{Km}$ de distância. A maior frequência do deslocamento dos rurais em torno do circuito dos pequenos municípios adjacentes ao seu de origem, chamou a atenção para o papel que os mesmos desempenham na vida dos rurais. Os pequenos municípios têm despertado interesse de diferentes campos da ciência dado à sua representatividade em escala nacional. Conforme o IBGE, os municípios com até 20 mil habitantes, representavam em 2010 mais de $80 \%$ do total dos municípios brasileiros. Os pequenos municípios têm se consolidado como importantes espaços de consumo frente as dinâmicas sociais e econômicas decorrentes do processo de desconcentração urbana vivido no Brasil, pósdécada de 1980, como enfatiza Corrêa (1999); Bell \& Jayne (2009); Fresca (2010) e Moreira Junior (2013). Todavia, o uso da nomenclatura pequena cidade ou pequeno município ainda não são unânimes na comunidade científica, dada a variedade de aspectos que circundam a caracterização destas unidades territoriais. Conforme (MAIA, 2010, p.16) a urbanização brasileira vem apresentando novos contornos, face ao crescimento anteriormente observado das grandes cidades e metrópoles. No mesmo sentido, Matos (2005, p.34) argumenta que o processo de urbanização brasileira nas últimas décadas vem se interiorizando através de redes articuladas às cidades de médio porte. Este fenômeno fez surgir uma plêiade de pequenas cidades associadas ao processo de desconcentração econômica e demográfica. Sobre este cenário, Corrêa (1999, p.50) advoga que no final do século $X X$ houve uma refuncionalização dos pequenos municípios. Primeiro, através da perda de centralidade da cidade e, segundo, em função do surgimento de novas atividades nos pequenos municípios, induzidas de fora ou criadas internamente. Esta dinâmica econômica conferiu um impulso produtivo ao núcleo preexistente, inserindo-o, diferentemente, na rede urbana e nela introduzindo uma nova divisão territorial do trabalho. Assim, os pequenos municípios que detinham status de estagnados ou perdedores de população passaram a ser interesse do capital. Casaril \& Sampaio (2016, p.240) destacam inclusive, como a presença de indústrias nestes pequenos municípios ou em centros urbanos próximos a eles estimulou movimentos populacionais de curta distância.

Neste interim, Marengo \& Rainer (2014, p.12) discutem que a conjuntura atual da urbanização no Brasil, sobrelevou os papeis dos pequenos municípios dando a eles uma diversidade de funções que dialogam com demandas verticais e horizontais. As demandas 


\section{OS RURAIS E A CIDADE: A MOBILIDADE SOCIOESPACIAL DOS HABITANTES DO CAMPO EM PEQUENOS MUNICÍPIOS DE ECONOMIA AGRÍCOLA}

verticais corresponderiam a intervenção dos agentes hegemônicos através da construção de redes e de infraestruturas que possibilitariam um volume maior de informações materiais e imateriais. Por conseguinte, uma intensidade maior de trocas entre municípios dos mais variados portes. Já as demandas horizontais decorreriam do entorno do pequeno município ou de seu próprio espaço intraurbano, como a instalação de infraestruturas urbanas capazes de assegurar as mais diversas necessidades da população local. De fato, os pequenos municípios brasileiros formam um cenário complexo e dinâmico, por isto a necessidade de entendê-los nas suas singularidades.

Este estudo adotou a classificação da Organização das Nações Unidas (ONU) que atribui ao pequeno município um contingente populacional de até 20.000 mil habitantes e densidade demográfica menor que $80 \mathrm{hab} / \mathrm{Km}^{2}$. A adoção desta classificação se justifica em função de que, no Brasil, os critérios utilizados para caracterizar os municípios seguem parâmetros político-administrativos que datam de 1938. Assim, em função de aproximadamente $80 \%$ dos municípios brasileiros não ultrapassarem os 20.000 habitantes e, pelo fato de que dentro deste grupo, os municípios com perfil agrícola representam quase a sua totalidade, utilizou-se neste trabalho a classificação da ONU.

$\mathrm{O}$ próprio IBGE dialogando mais proximamente com a literatura acadêmica e com instituições internacionais como a OCDE (Organização para a Cooperação e o Desenvolvimento Econômico) buscou superar a inconsistência dos critérios de cunho políticoadministrativo de classificação dos municípios brasileiros utilizando uma combinação de critérios, envolvendo o tamanho da população, a densidade demográfica, o tempo de deslocamento de seus moradores a centros urbanos com mais de 50 mil habitantes para a caracterização do mesmo. Santos (1979a, p.227) também sugeriu uma classificação aplicável aos municípios brasileiros e criou três categorias principais para observar os espaços urbanos: "cidades locais", "cidades regionais" e "metrópoles". Para este autor, as cidades regionais concentrariam economias de escala e mercados consumidores mais amplos, tendo uma ligação direta com as metrópoles e funcionando como um ponto de apoio para as cidades menores. Já as cidades locais seriam referentes aos pequenos municípios, com uma aglomeração capaz de responder às necessidades vitais mínimas de sua população e de seu entorno, com as vilas e as áreas rurais.

Deste modo, as redes urbanas variam de acordo com o seu padrão espacial e a sua complexidade funcional assumindo um caráter de maior ou menor centralidade do ponto de vista econômico. Santos (1979b, p.74) verificou uma interdependência entre as cidades em uma tendência piramidal, em que as cidades de mesmo nível recorreriam às de nível superior em termos de oferta de produtos e serviços, etc. As cidades locais seriam marcadas em grande medida pela ampla interdependência com o campo e vice-versa, estabelecendo trocas materiais e imateriais reforçadas pelo avanço do processo de urbanização.

Alves \& Silva (2015, p.16) apoiados nos estudos de Baeninger (1998, p.74) sublinham que as mudanças relacionadas com a reestruturação produtiva contribuem para o desenvolvimento e consolidação de novos polos intra e interregionais. Se outrora, as pequenas cidades eram caracterizadas por uma economia prioritariamente agrícola e por relações e influências circunscritas ao seu entorno, hoje elas se transformam em cidades econômicas, em decorrência dos avanços técnico-científicoinformacionais, difundidos pela globalização (SANTOS, 1979, p. 23-27). Diante das transformações ocorridas na organização espacial das pequenas cidades decorridas das inovações tecnológicas e das alterações nas relações de produção e trabalho, o referido autor advoga que a cidade torna-se o lócus da regulação do que se faz no campo (SANTOS, 1993, p. 51). No caso específico da Microrregião de Viçosa (Figura 1), observa-se que esta é composta por 20 pequenos 


\section{OS RURAIS E A CIDADE: A MOBILIDADE SOCIOESPACIAL DOS HABITANTES DO CAMPO EM PEQUENOS MUNICÍPIOS DE ECONOMIA AGRÍCOLA}

municípios, que contam com no máximo 20 mil

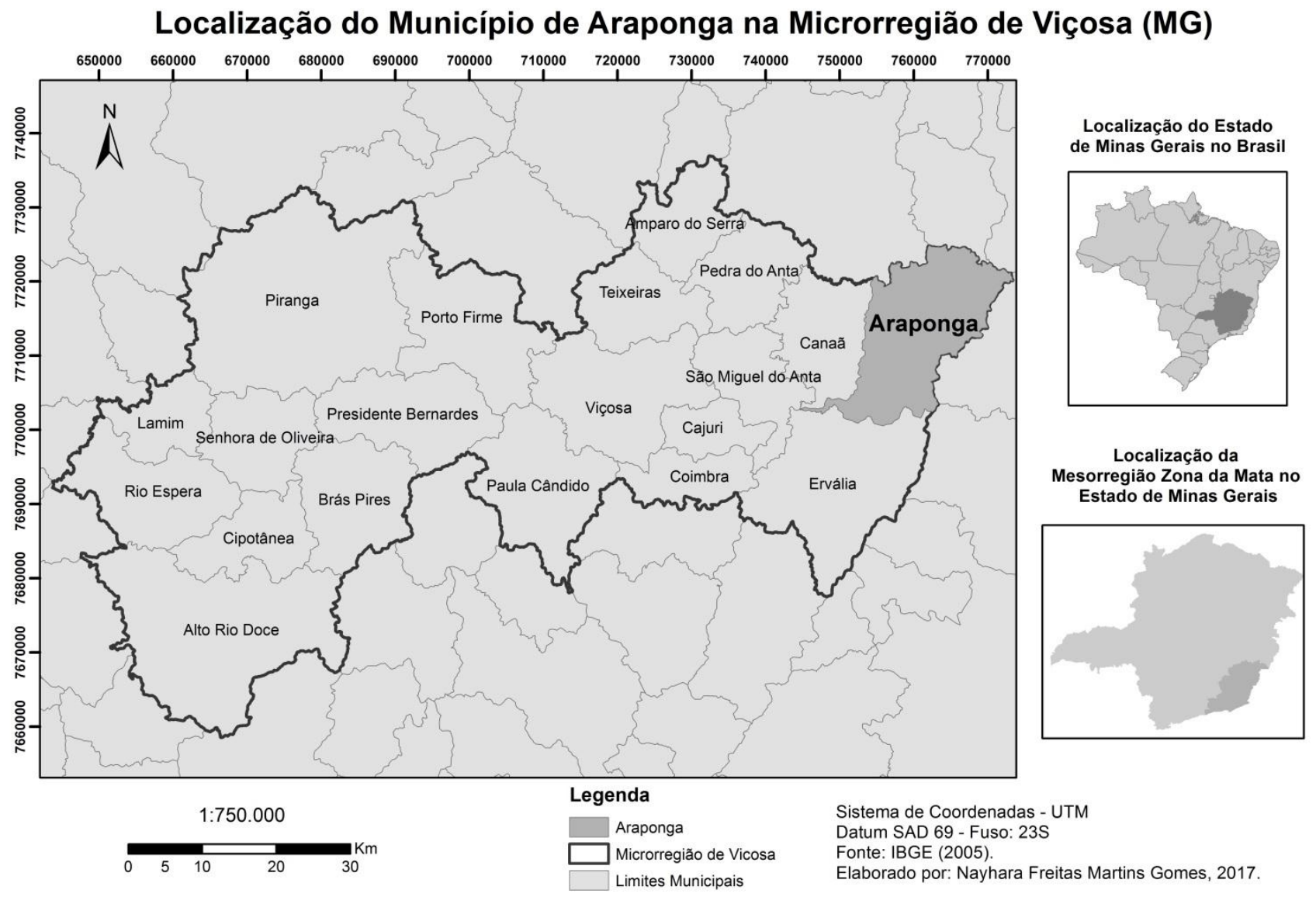

Figura 1- Mapa da Microrregião de Viçosa (MG) com ênfase no pequeno município de Araponga.

Quanto ao caráter diferenciado de Viçosa face aos demais municípios da microrregião, este se faz notar no seu tamanho populacional, mas, também, na diversidade de serviços que oferece, principalmente, no âmbito educacional, o que lhe garante uma posição de centralidade frente às demais cidades ao seu entorno. A trama social e espacial dos pequenos municípios da Microrregião de Viçosa (Tabela 1), na Mesorregião da Zona da Mata mineira deve ser pensada considerando, por um lado, as características de ruralidade de seus municípios, visto a expressividade da população rural frente a citadina, ademais, estes municípios são sustentados por uma economia ainda fortemente amparada na agricultura. Contudo, é importante considerar que esta economia agrícola é dirigida pela lógica produtiva advinda do mercado globalizado e de centros urbanos maiores. 
GOMES, M. F. M., FIÚZA, A. L. C., PINTO, N. M. A., REMOALDO, P. C. A. C.

\section{OS RURAIS E A CIDADE: A MOBILIDADE SOCIOESPACIAL DOS HABITANTES DO CAMPO EM PEQUENOS MUNICÍPIOS DE ECONOMIA AGRÍCOLA}

Tabela 1 - Dimensões territoriais e demográficas da microrregião de Viçosa

\begin{tabular}{|c|c|c|c|c|}
\hline Município & $\begin{array}{c}\text { Densidade } \\
\text { Demográfica } \\
\left(\mathrm{Hab} / \mathrm{Km}^{2}\right)\end{array}$ & $\begin{array}{c}\text { População } \\
\text { Total }\end{array}$ & $\begin{array}{c}\text { População } \\
\text { Rural }\end{array}$ & $\begin{array}{c}\text { População } \\
\text { Urbana }\end{array}$ \\
\hline Alto Rio Doce & 23,5 & 12.159 & 7.089 & 5.070 \\
\hline Amparo do Serra & 34,6 & 5.053 & 2.411 & 2.642 \\
\hline Araponga & 26,8 & 8.152 & 5.111 & 3.041 \\
\hline Brás Pires & 20,8 & 4.637 & 2.414 & 2.223 \\
\hline Cajuri & 48,7 & 4.047 & 1.951 & 2.096 \\
\hline Canaã & 26,5 & 4.628 & 2.769 & 1.859 \\
\hline Cipotânea & 42,7 & 6.547 & 3.533 & 3.014 \\
\hline Coimbra & 66,0 & 7.054 & 1.898 & 5.156 \\
\hline Ervália & 50,2 & 17.946 & 8.476 & 9.470 \\
\hline Lamim & 29,1 & 3.452 & 1.941 & 1.511 \\
\hline Paula Cândido & 34,6 & 9.271 & 4.335 & 4.936 \\
\hline Pedra do Anta & 20,6 & 3.365 & 1.173 & 2.192 \\
\hline Piranga & 26,2 & 17.232 & 11.274 & 5.958 \\
\hline Porto Firme & 36,6 & 10.417 & 5.586 & 4.831 \\
\hline Presidente Bernardes & 23,4 & 5.537 & 3.895 & 1.642 \\
\hline Rio Espera & 25,4 & 6.070 & 3.667 & 2.403 \\
\hline São Miguel do Anta & 44,4 & 6.760 & 3.014 & 3.746 \\
\hline Senhora de Oliveira & 33,3 & 5.683 & 2.427 & 3.256 \\
\hline Teixeiras & 68,1 & 11.355 & 3.732 & 7.623 \\
\hline Viçosa & 241,2 & 72.220 & 4.915 & 67.305 \\
\hline
\end{tabular}

Fonte: IBGE, Censo Demográfico, 2010.

De acordo com os dados censitários do IBGE entre as cidades da Microrregião de Viçosa o crescimento populacional no período de 2000 e 2010 foi predominantemente baixo ou negativo. Em muitas unidades territoriais tal crescimento inclusive foi inferior à média do estado de Minas Gerais (0,09\%). Excetua-se o caso da cidade polo de Viçosa que apresenta a maior taxa de crescimento demográfico da região $(1,08 \%)$ numericamente superior à taxa de crescimento médio do Sudeste e do Brasil (1,05\% e 1,17\%), respectivamente, conforme IBGE (2010). Já o pequeno município de Araponga, aqui analisado, registrou para o mesmo período o crescimento populacional ligeiramente positivo de 0,29\%. Silveira (2014, p.81) ao estudar o pequeno município e seu papel na rede urbana da Microrregião de Viçosa compreendeu que as interações dos habitantes do campo com agentes e instituições situadas nas sede dos pequenos municípios se constituía na sua forma de conexão mais imediata e corriqueira.

A intensificação da mobilidade socioespacial, ou seja, o aumento do número diário de deslocamentos nos últimos anos tem se constituído em um fato social verificado ao redor do mundo (BAUMAN, 2001). No entanto, na pesquisa realizada no pequeno município de Araponga a avaliação dos rurais em relação à acessibilidade a outros municípios (Tabela 2), como também, até mesmo para a sede do próprio município foi considerada, no geral, como difícil. Contudo, a negatividade desta avaliação pode estar mais relacionada as condições da estrada do que ao acesso aos meios de transporte. Estes últimos foram considerados, em larga escala, como adequados para a realização do deslocamento no sentido campovila-cidade e vice versa. Este dado indica que o meio de transporte independente da faixa etária 
GOMES, M. F. M., FIÚZA, A. L. C., PINTO, N. M. A., REMOALDO, P. C. A. C.

\section{OS RURAIS E A CIDADE: A MOBILIDADE SOCIOESPACIAL DOS HABITANTES DO CAMPO EM PEQUENOS MUNICÍPIOS DE ECONOMIA AGRÍCOLA}

ou gênero não se constituía em um fator limitador para o deslocamento.

Tabela 2 - Avaliação quanto a condição de deslocamento para outros municípios.

\begin{tabular}{|c|c|c|c|c|c|c|}
\hline \multirow{3}{*}{$(\%)$} & \multicolumn{6}{|c|}{ Respondentes por geração e sexo } \\
\hline & \multicolumn{2}{|c|}{ Jovens } & \multicolumn{2}{|c|}{ Adultos } & \multicolumn{2}{|c|}{ Idosos } \\
\hline & $\mathrm{H}$ & $\mathrm{M}$ & $\mathrm{H}$ & $\mathrm{M}$ & $\mathrm{H}$ & $\mathrm{M}$ \\
\hline $\begin{array}{l}\text { Fácil devido à proximidade e condição } \\
\text { das estradas }\end{array}$ & 15,0 & 12,5 & 21,7 & 4,5 & 33,3 & 14,3 \\
\hline $\begin{array}{l}\text { Fácil devido ao meio de transporte } \\
\text { utilizado e a proximidade }\end{array}$ & 10,0 & 25,0 & 21,7 & 27,3 & 50,0 & \\
\hline $\begin{array}{l}\text { Difícil em decorrência do tipo de } \\
\text { transporte e por depender de } \\
\text { transporte alheio }\end{array}$ & 35,0 & 37,5 & 21,7 & 31,8 & & 28,6 \\
\hline $\begin{array}{l}\text { Difícil devido a condição das estradas e } \\
\text { a distância }\end{array}$ & 40,0 & 25,0 & 34,8 & 31,8 & 16,7 & 42,9 \\
\hline Não se desloca & & & & 4,5 & & 14,3 \\
\hline
\end{tabular}

Fonte: Inquérito por questionário semi-estruturado, realizado no município de Araponga, MG.

No que tange à avaliação relativa à capacidade do município atender às demandas das pessoas que vivem no campo, a avaliação foi negativa, em todas as faixas etárias e gênero, com exceção das idosas, que foram menos céticas. De acordo com Endlich (2006, p. 69) as pequenas cidades embora possam apresentar potencial para fortalecerem o intercâmbio comercial entre elas, ainda são muito carentes da prestação de serviços. Os dados aqui apresentados corroboram com o trabalho de Silveira (2014, p.48) quando a autora verifica que os pequenos municípios da Microrregião de Viçosa apresentam frágil dinamismo, apresentando grande dependência em relação ao polo microrregional.

De acordo com os dados apresentados na Tabela 3, os fatores mais débeis na prestação de serviço por parte do pequeno município em questão encontravam-se vinculados à falta de atendimento médico especializado; existência de equipamentos nos postos de saúde, meios para continuar os estudos; acesso a comércio de qualidade (variedade e qualidade de itens) e segurança pública (policiamento eficiente).

Em função disto, o deslocamento para cidades polo, como Viçosa, torna-se corriqueiro, já que estas cidades polos desempenham papel de centralidade regional, atendendo de forma mais ampla às demandas dos moradores de pequenos municípios. Todavia, ainda que os serviços oferecidos nos pequenos municípios tenham um caráter mais básico, as mulheres mais que os homens apresentaram uma avaliação mais positiva dos serviços existentes no próprio município no qual viviam, afirmando que este atendia, em parte, às suas necessidades. 
GOMES, M. F. M., FIÚZA, A. L. C., PINTO, N. M. A., REMOALDO, P. C. A. C.

\section{OS RURAIS E A CIDADE: A MOBILIDADE SOCIOESPACIAL DOS HABITANTES DO CAMPO EM PEQUENOS MUNICÍPIOS DE ECONOMIA AGRÍCOLA}

Tabela 3 - Avaliação quanto ao atendimento das necessidades no município.

\begin{tabular}{|c|c|c|c|c|c|c|}
\hline \multirow{3}{*}{$(\%)$} & \multicolumn{6}{|c|}{ Respondentes por geração e sexo } \\
\hline & \multicolumn{2}{|c|}{ Jovens } & \multicolumn{2}{|c|}{ Adultos } & \multicolumn{2}{|c|}{ Idosos } \\
\hline & $\mathrm{H}$ & $\mathrm{M}$ & $\mathrm{H}$ & $\mathrm{M}$ & $\mathrm{H}$ & $\mathrm{M}$ \\
\hline $\begin{array}{l}\text { Atende (por ter banco, lotérica, médico de } \\
\text { plantão e EMATER) }\end{array}$ & 30,0 & 25,0 & 17,4 & 27,3 & 16,7 & 28,6 \\
\hline $\begin{array}{l}\text { Não atende (falta recursos principalmente, } \\
\text { para a saúde, para estudo, comércio de } \\
\text { qualidade e segurança pública) }\end{array}$ & 50,0 & 50,0 & 43,5 & 31,8 & 66,7 & 42,9 \\
\hline Em partes (há dependência de outras & & & & & & \\
\hline $\begin{array}{l}\text { cidades, falta recursos principalmente para } \\
\text { a saúde e comércio de qualidade) }\end{array}$ & 20,0 & 25,0 & 39,1 & 40,9 & 16,7 & 28,6 \\
\hline
\end{tabular}

Fonte: Inquérito por questionário semi-estruturado, realizado no município de Araponga, MG.

Para Wagner (2014, p.173), os vínculos que conectam os indivíduos que vivem no campo à cidade formam um conjunto de laços marcados por vieses de gênero, geração e classe social. A seguir, apresentar-se-á os dados referentes ao deslocamento dos indivíduos que vivem no campo para o próprio campo ou para a cidade, para trabalhar, estudar, fazer compras, buscar serviços de saúde e realizar atividades de lazer.
Quanto ao deslocamento para trabalhar constatou-se que ele se dava com maior expressividade dentro da própria comunidade, sendo que os rapazes se deslocavam mais que as moças: $45 \%$ contra $19 \%$. Em relação aos adultos a situação se inverteu: os homens se deslocavam menos do que entre as mulheres: $26 \%$ contra $36 \%$, respectivamente. Já entre os idosos, tanto os homens quanto as mulheres não saíam mais do espaço de origem para trabalhar (Tabela 4).

Tabela 4 - Deslocamento para trabalhar, segundo a geração e o sexo.

\begin{tabular}{|c|c|c|c|c|c|c|}
\hline \multirow{3}{*}{ (\%) } & \multicolumn{6}{|c|}{ Respondentes por geração e sexo } \\
\hline & \multicolumn{2}{|c|}{ Jovens } & \multicolumn{2}{|c|}{ Adultos } & \multicolumn{2}{|c|}{ Idosos } \\
\hline & $\mathrm{M}$ & $\mathrm{F}$ & M & $\mathrm{F}$ & $\mathrm{M}$ & $\mathrm{F}$ \\
\hline NA* & 15,0 & 50,0 & 47,8 & 45,5 & 100 & 100 \\
\hline Para a própria comunidade onde reside & 45,0 & 18,8 & 26,1 & 36,4 & & \\
\hline Para outra comunidade rural do próprio município & 20,0 & 6,3 & & 4,5 & & \\
\hline Para o distrito do próprio município & & 6,3 & & & & \\
\hline $\begin{array}{l}\text { Para a própria comunidade e para outras } \\
\text { comunidades rurais do município }\end{array}$ & 10,0 & 18,8 & 21,7 & 13,6 & & \\
\hline Para o centro urbano do próprio município & & & 4,3 & & & \\
\hline $\begin{array}{l}\text { Para o centro urbano do próprio município e para } \\
\text { outras comunidades rurais do próprio município }\end{array}$ & 5,0 & & & & & \\
\hline Para outro pequeno município vizinho & 5,0 & & & & & \\
\hline
\end{tabular}

Notas: *Não se aplica (refere-se aos respondentes que não realizam tal ação)

Fonte: Inquérito por questionário semi-estruturado, realizado no município de Araponga, MG.

No que diz respeito aos meios de transporte utilizados nos deslocamentos realizados pelos rurais para trabalhar, a moto destacou-se como a mais utilizada: $65 \%$ dos rapazes entrevistados utilizavam-na para esta finalidade, assim como $26 \%$ dos homens adultos, 
GOMES, M. F. M., FIÚZA, A. L. C., PINTO, N. M. A., REMOALDO, P. C. A. C.

\section{OS RURAIS E A CIDADE: A MOBILIDADE SOCIOESPACIAL DOS HABITANTES DO CAMPO EM PEQUENOS MUNICÍPIOS DE ECONOMIA AGRÍCOLA}

$25 \%$ das moças e $18 \%$ das mulheres adultas. A moto foi considerada um meio de deslocamento flexível e veloz em comparação aos demais meios de transporte, sendo que o carro próprio não foi citado como um meio comum de transporte. Dentre os meios de transporte não automotores, como a charrete, as mulheres adultas foram as maiores usuárias (Tabela 5).

Tabela 5 - Meio de transporte utilizado para trabalhar.

\begin{tabular}{lcccc}
\hline \multirow{2}{*}{$(\%)$} & \multicolumn{4}{c}{ Respondentes por geração e sexo } \\
\cline { 2 - 5 } & \multicolumn{3}{c}{ Jovens } & \multicolumn{3}{c}{ Adultos } \\
\cline { 2 - 5 } & 15,0 & 50,0 & 47,8 & $\mathrm{~F}$ \\
\hline NA & & & 4,3 & \\
Carro próprio & 65,0 & 25,0 & 26,1 & 18,2 \\
Moto própria & 20,0 & 18,8 & 21,7 & 36,4 \\
Não automotores & & 6,3 & & \\
Trator & & & \\
\hline
\end{tabular}

Fonte: Inquérito por questionário semi-estruturado, realizado no município de Araponga, MG.

Observou-se, assim, que em relação à mobilidade para trabalhar se dava, majoritariamente, dentro das próprias localidades rurais e que o meio de transporte mais utilizado foi a moto, excetuando na condição das mulheres adultas que utilizavam meios de transporte não automotores. Observouse que no município de Araponga, $73,61 \%$ das pessoas estavam ocupadas no setor primário da economia. Este é um dado que merece pesquisas mais aprofundadas, no sentido de se investigar a força da economia cafeeira na manutenção da população do município em nível local. As ocupações desenvolvidas pelos entrevistados mostraram justamente a predominância das atividades agrícolas, dentre as quais as atividades relacionadas ao café se destacam. Os dados da pesquisa revelaram que os homens estavam mais envolvidos com elas nos três grupos etários (Tabela

6).

Tabela 6 - Tipo de ocupação por geração e sexo.

\begin{tabular}{lcccccc}
\hline & \multicolumn{5}{c}{ Respondentes por geração e sexo } \\
\cline { 2 - 6 } & \multicolumn{2}{c}{ Jovens } & Adultos & \multicolumn{1}{c}{ Idosos } \\
\cline { 2 - 6 } & $\mathrm{M}$ & $\mathrm{F}$ & $\mathrm{M}$ & $\mathrm{F}$ & $\mathrm{M}$ & $\mathrm{F}$ \\
\hline Agricultor(a) & 40,0 & 37,5 & 69,6 & 54,5 & 50,0 \\
Estudante & 5,0 & 6,3 & & & \\
Atividade agrícola e não & 15,0 & & 26,1 & 4,5 & 16,7 \\
agrícola & & & & & \\
Estudante e lavrador & 25,0 & 12,5 & & & \\
Atividade não agrícola & 10,0 & 6,3 & & 13,6 & \\
Trabalhador assalariado & 5,0 & & &
\end{tabular}

Doméstica

6,3

33,3 100,0

Aposentado (a)

4,5

Fonte: Inquérito por questionário semi-estruturado, realizado no município de Araponga, MG.

Quanto ao rendimento mensal domiciliar declarado pelos respondentes (Tabela
7), este girava, nas famílias com entrevistados mais jovens e com adultos, em média, próximo a 
GOMES, M. F. M., FIÚZA, A. L. C., PINTO, N. M. A., REMOALDO, P. C. A. C.

\section{OS RURAIS E A CIDADE: A MOBILIDADE SOCIOESPACIAL DOS HABITANTES DO CAMPO EM PEQUENOS MUNICÍPIOS DE ECONOMIA AGRÍCOLA}

um salário mínimo e meio ( $\mathrm{R} \$ 1100,00)$. Os maiores ganhos foram encontrados nas famílias com idosos do sexo masculino, nas quais a renda se aproximava de $\mathrm{R} \$ 2675,00$, seguida pelas famílias com idosas, cuja renda ficou em torno de $\mathrm{R} \$ 1432,00$. Nestas famílias com idosos, para além da renda advinda da atividade agrícola soma-se a renda advinda da aposentadoria.

Tabela 7: Rendimento mensal familiar.

\begin{tabular}{ccccccc}
\hline Respondente & Sexo & Frequência & Mínimo & Máximo & Média & S \\
\hline \multirow{2}{*}{ Jovem } & Masculino & 20 & 350 & 2500 & 1031,0 & 613,8 \\
& Feminino & 16 & 200 & 3000 & 1168,8 & 781,6 \\
\hline \multirow{2}{*}{ Adulto } & Masculino & 23 & 250 & 7500 & 1158,7 & 1495,9 \\
& Feminino & 22 & 300 & 2500 & 1034,1 & 699,7 \\
\hline \multirow{2}{*}{ Idoso } & Masculino & 6 & 1450 & 4000 & 2675,0 & 1022,6 \\
& Feminino & 7 & 724 & 2000 & 1432,0 & 371,9 \\
\hline
\end{tabular}

Fonte: Inquérito por questionário semi-estruturado, realizado no município de Araponga, MG.

Já no que diz respeito ao deslocamento para estudar, este mostrou-se restrito aos jovens, embora mesmo entre eles pouco frequente. Observou que (65\%) dos rapazes e (75\%) das moças nunca se deslocavam para estudar. Entre os jovens que estudavam, a maior parte frequentava as escolas do próprio município. Todavia, se o trabalho e o estudo não se constituíram em motivações para os indivíduos que vivem neste pequeno município, de economia cafeeira, se deslocarem das localidades rurais para a sede do município, o deslocamento para realizar compras de uso pessoal, sim, trouxe esta motivação.

O deslocamento comprar roupas e calçados se constituiu em uma realidade entre todas as gerações de respondentes. Entre os jovens, $90 \%$ dos rapazes (90\%) e $87,5 \%$ das moças se deslocavam do campo para a cidade com esta finalidade. Quanto aos adultos, os homens deslocavam-se menos para as atividades de consumo do que as mulheres: $73,9 \%$ contra $90,9 \%$, respectivamente. A mesma tendência se manteve entre os idosos: $50 \%$ dos senhores se deslocavam para consumir contra $85,7 \%$ das senhoras. Segundo Candido (2010, p. 217), o consumo pode ser tomado como um importante indicador das mudanças nos modos de vida do caipira paulista face ao contato das sociedades rurais com a urbano-industrial.
Quanto à frequência do consumo, observou-se que a prática mais comum era a do deslocamento mensal para fazer compras: entre os jovens, $37 \%$ das moças e $20 \%$ dos rapazes se deslocavam mensalmente para este fim. A mesma tendência de gênero se manteve entre os adultos: $23 \%$ das mulheres e $9 \%$ dos homens se deslocavam mensalmente para fins de consumo. Por fim, entre os idosos, $43 \%$ das Senhoras e $17 \%$ dos Senhores. Ou seja, o deslocamento para realizar atividades de consumo de uso pessoal evidenciou uma clara marca de gênero, sendo que as mulheres idosas foram as que mais se deslocavam para este fim, seguidas das moças, $43 \%$ e $37 \%$, respectivamente.

Entre os que menos se deslocavam com fins de consumo, estavam os idosos do sexo masculino, $50 \%$ deles nunca se deslocam para consumir. Quanto aos destinos procurados para a realização das compras de uso pessoal, os deslocamentos realizados tendo como destino o distrito do próprio município de origem foram mais realizados pelas mulheres adultas e pelas idosas: $50 \%$ e $43 \%$, respectivamente. Percebeuse, assim, que o deslocamento para a realização de consumo relacionado a bens de uso pessoal, como roupa e calçado se dava, preferencialmente, dentro do próprio município, sendo muito pequeno o deslocamento para o município polo da região para esta finalidade. 


\section{OS RURAIS E A CIDADE: A MOBILIDADE SOCIOESPACIAL DOS HABITANTES DO CAMPO EM PEQUENOS MUNICÍPIOS DE ECONOMIA AGRÍCOLA}

Ficou evidente, portanto, a importância do comércio a nível local para a vida dos rurais.

Constatou-se que perante os corriqueiros deslocamentos entre o campo e a cidade, os rurais circulavam e se apropriavam do espaço citadino motivados por necessidades diversas. Ademais, se apropriam de espaços públicos, privados e da mescla destes. Sobretudo, frequentam localidades para realizar atividades ligadas ao comércio e a prestação de serviços, que orientam à construção de espacialidades econômicas. A diversificação do comércio no município é um dos fatores que tem influência no desenho destas interações espaciais entre os espaços de origem e destino. Percebeu-se também que o deslocamento para fora do município de origem em busca de serviços especializados como em saúde e em educação é uma realidade que se cumpre pelos habitantes do campo.

Quanto aos meios de transporte utilizados para as compras de bens de uso pessoal, $65 \%$ dos rapazes e $43,5 \%$ dos homens adultos utilizavam a moto. Já as mulheres utilizavam mais o ônibus: $25 \%$ das moças, $54 \%$ das mulheres adultas e $43 \%$ das Senhoras. As moças eram as que mais utilizavam os meios de transporte não automotores, indo a pé aos seus destinos. Já o carro era mais utilizado pelos Senhores idosos: 33,3\%. Observa-se, portanto, que os homens detinham maior acesso aos meios de transporte com maior flexibilidade $\mathrm{e}$ autonomia de deslocamento, como a moto e o carro. Já as mulheres utilizavam os meios de transporte com maior dependência de horário, como o ônibus, ou mais lentos, como os meios de transporte não automotores. Em relação ao ato de se deslocar para fazer compras para a casa (alimentos e produtos de limpeza), os homens, adultos e idosos, foram os maiores compradores, seguidos pelas idosas, o que sugere que o poder de consumo pode exercer uma forte influência em relação a quem realiza as compras para a casa (Tabela

Tabela 8 - Frequência do deslocamento para compras de uso doméstico.

\begin{tabular}{ccccccc}
\hline & \multicolumn{5}{c}{ Respondentes por geração e sexo } \\
\cline { 2 - 7 }$(\%)$ & \multicolumn{2}{c}{ Jovens } & \multicolumn{2}{c}{ Adultos } & \multicolumn{2}{c}{ Idosos } \\
\cline { 2 - 7 } & $\mathrm{M}$ & $\mathrm{F}$ & $\mathrm{M}$ & $\mathrm{F}$ & $\mathrm{M}$ & $\mathrm{F}$ \\
\hline Nunca & 50,0 & 62,5 & 8,7 & 45,5 & 16,7 & 28,6 \\
Mais de 1x/semana & & & & & & 14,3 \\
Uma x/mês & 25,0 & 25,0 & 56,5 & 45,5 & 16,7 & 42,9 \\
Mais de 1x/mês & 20,0 & 12,5 & 34,8 & 9,1 & 66,7 & 14,3 \\
Algumas x/ano & 5,0 & & & & & \\
\hline
\end{tabular}

Fonte: Inquérito por questionário semi-estruturado, realizado no município de Araponga, MG.

As relações econômicas expressas por meio da inserção em circuitos mercantis é um dos fatores geradores da mobilidade socioespacial que integra a sociedade rural com a sociedade englobante constituindo as relações econômicas formas de mediação que quebram o isolamento daqueles que vivem afastados dos núcleos de povoamento. Na situação estudada percebeu-se que a dimensão econômica teve significativa importância para integrar o campo e a cidade, através da venda e compra de produtos agrícolas como o café que é feita por atravessadores que buscam a produção da colheita na propriedade ou os agricultores se deslocam à cidade para oferecer a produção colhida. Esta ocasião de ida a cidade para a negociação da produção, compra de combustíveis e remédios, recebimento de aposentadorias ou alguma eventualidade permite também a aquisição de outros produtos manufaturados nas mercearias e "vendas".

Quanto aos locais procurados para comprar bens para a casa, os homens de todas as gerações e as idosas buscavam o centro urbano 


\section{OS RURAIS E A CIDADE: A MOBILIDADE SOCIOESPACIAL DOS HABITANTES DO CAMPO EM PEQUENOS MUNICÍPIOS DE ECONOMIA AGRÍCOLA}

do próprio município. Por seu turno, as moças (19\%) e as mulheres adultas (23\%) buscavam o distrito local para fazerem as suas compras. Talvez, pelo fato de terem menor poder econômico e por ser mais fácil obter crédito por serem da própria comunidade. Observou-se, assim, que também em relação ao consumo de bens domésticos, o município supria as principais demandas dos moradores do campo. Os gêneros alimentícios, artefatos pessoais e artigos de vestuário eram comprados na cidade, mas havia momentos que estes gêneros eram comprados também no distrito do município.

A mesma situação se manifestou em relação ao deslocamento para a realização de compras para a propriedade, tais como insumos agrícolas e equipamentos. Este configurou-se como predominantemente masculino e efetivado majoritariamente pelos homens adultos e pelos idosos. Esta não era uma incumbência nem dos rapazes e menos ainda das moças, tão pouco das mulheres adultas e das Senhoras idosas. 0 pequeno município em estudo por possuir uma economia pautada na produção do café, produto este que sofre severas oscilações do mercado, permite com que os rurais exerçam profundas influências no espaço citadino local. Entretanto, o pequeno município estabelece poucas interações e não exerce domínio sobre outros do entorno, tendo influência demarcada no nível local, uma vez que é no campo que se tem a primazia das suas relações econômicas. A economia destas pequenas cidades praticamente não promove expressivas trocas e fluxos entre elas, mas configura-se como o local preferencial de realização de compras e busca de serviços.

Saindo da esfera do consumo e passando para a esfera da saúde percebeu-se que o deslocamento dos rurais dentro do próprio município também predominou, manifestando, entretanto, um recorte de gênero e geração. 0 município de residência foi o mais procurado por homens e mulheres de todas as gerações, com exceção dos idosos. Em particular, os homens, que buscavam, em um percentual acima de $50 \%$, os serviços mais especializados na cidade polo da região (Viçosa) e na capital do Estado (Belo Horizonte), ao contrário das mulheres idosas, as quais procuravam com maior frequência o posto de saúde da própria comunidade e o da sede do próprio município, do que assistência médica na cidade polo da microrregião.

As situações mais simples são resolvidas na sede municipal, já nos casos mais graves que necessitam de atendimento em consultas médicas especializadas e realização de exames, há procura pela cidade polo da microrregião (Viçosa). As famílias que dispõe de melhores condições econômicas recorrem ao atendimento médico em outras cidades, onde consideram que o serviço médico privado seja mais qualificado, rápido e acessível em termos financeiros. Além do acesso aos serviços públicos a participação política dos rurais está vinculada a sede municipal, uma vez que na cidade estão as sedes administrativas dos órgãos estatais e do Sindicato de Trabalhadores Rurais.

No que diz respeito aos serviços bancários (Tabela 9), observou-se que a frequência de deslocamento predominante para a realização dos mesmos foi mensal, estando os fluxos vinculados predominantemente ao centro urbano do próprio município e tendo a maior predominância de mulheres, idosas e adultas. Tal fato se dá sobretudo, ao pagamento da aposentadoria e retirada de benefícios de outros programas assistencialistas do governo, como o Bolsa Família, que predominantemente são uma tarefa conferida às mulheres rurais. 
GOMES, M. F. M., FIÚZA, A. L. C., PINTO, N. M. A., REMOALDO, P. C. A. C.

\section{OS RURAIS E A CIDADE: A MOBILIDADE SOCIOESPACIAL DOS HABITANTES DO CAMPO EM PEQUENOS MUNICÍPIOS DE ECONOMIA AGRÍCOLA}

Tabela 9 - Destino do deslocamento para realizar serviços bancários.

\begin{tabular}{|c|c|c|c|c|c|c|}
\hline \multirow{3}{*}{$(\%)$} & \multicolumn{6}{|c|}{ Respondentes por geração e sexo } \\
\hline & \multicolumn{2}{|c|}{ Jovens } & \multicolumn{2}{|c|}{ Adultos } & \multicolumn{2}{|c|}{ Idosos } \\
\hline & $\mathrm{M}$ & $\mathrm{F}$ & $\mathrm{M}$ & $\mathrm{F}$ & $\mathrm{M}$ & $F$ \\
\hline NA & 50 & 75 & 30,4 & 36,4 & & 14,3 \\
\hline Para o centro urbano do próprio município & 35 & 18,8 & 34,8 & 50 & 33,3 & 71,4 \\
\hline Para a cidade polo da microrregião & 10 & & 4,3 & 4,5 & 16,7 & \\
\hline $\begin{array}{l}\text { Para o centro urbano do próprio município e } \\
\text { para a cidade polo da microrregião }\end{array}$ & 5 & & 8,7 & & 16,7 & \\
\hline Para outros pequenos municípios vizinhos & & 6,3 & 17,4 & 4,5 & 16,7 & 14,3 \\
\hline $\begin{array}{l}\text { Para pequeno município vizinho e para outro } \\
\text { município da microrregião }\end{array}$ & & & 4,3 & & 33,3 & \\
\hline $\begin{array}{l}\text { Para o centro urbano do próprio município e } \\
\text { para outro pequeno município vizinho }\end{array}$ & & & & 4,5 & & \\
\hline $\begin{array}{l}\text { Para a cidade polo da microrregião e para } \\
\text { outro pequeno município vizinho }\end{array}$ & & & & & 16,7 & \\
\hline
\end{tabular}

Fonte: Inquérito por questionário semi-estruturado, realizado no município de Araponga, MG.

De maneira geral, podem-se traçar algumas considerações avaliando os deslocamentos realizados pelos rurais para 0 espaço urbano realizado, majoritariamente, dentro do próprio município. Percebeu-se que o evento "ir à rua" para comprar bens de uso pessoal, para a casa ou para a propriedade, efetivava uma vivência da cidade como um espaço de pertencimento. O fato de residirem no campo não fazia com que tomassem a "rua" (a cidade) como um espaço do qual não faziam parte, pelo contrário, a cidade era considerada parte integrante de suas vidas, compondo o binômio "casa e rua", o qual expressava a totalidade de sua espacialidade vivida. É notável que os rurais se deslocavam periodicamente à cidade com o intuito de consumir determinados produtos e serviços não encontrados no campo. A maioria segue a lógica do ir e voltar ao final do dia ou do cumprimento de suas necessidades, retornando à sua vida no campo e só retornando à rua após vários dias, outros tantos retornam somente no mês seguinte.

\section{CONSIDERAÇÕES FINAIS}

Este estudo evidenciou que a saída dos rurais do seu espaço de origem não está relacionada apenas à realização de atividades comerciais, os vínculos que mantém com a cidade vão além da realização das atividades produtivas. Algumas parcelas dos respondentes deslocam-se para lá com o objetivo não apenas de estabelecer relações mercantis, mas também de fazer visitas a parentes e amigos, frequentar festas e bares, torneios de futebol, participar de encontros religiosos e eventos políticos. Naquele espaço social são encontrados diversos ambientes de lazer onde são firmados e reafirmados laços sociais e diversas formas de sociabilidade entre as pessoas que formam a sociedade de interconhecimento.

"Ir à rua", expressão comumente usada pelos rurais para designar o deslocamento à cidade, expressa uma vivência da cidade como um espaço de pertencimento. Portanto, o sentimento de pertencimento está associado, dentre outros fatores, ao fato da cidade ser além de um lugar de negócio, um local de conhecimento e afinidade. Neste espaço social são firmados e reafirmados laços sociais e diversas formas de sociabilidade. Interessou-nos entender estas espacialidades como produto das relações sociais nela travadas e de seus movimentos e dinâmicas. Para tal, admitiu-se a espacialidade como uma experiência socioespacial dos rurais. 


\section{OS RURAIS E A CIDADE: A MOBILIDADE SOCIOESPACIAL DOS HABITANTES DO CAMPO EM PEQUENOS MUNICÍPIOS DE ECONOMIA AGRÍCOLA}

Para além das finalidades que direcionavam o deslocamento dos rurais para fora de seus espaços de origem, notou-se que tal fenômeno é predominantemente interno e circular, e que apresenta peculiaridades quanto ao gênero. A mobilidade dos habitantes do campo, se faz predominantemente dentro do pequeno município, sinalizando que, em certa medida, este pequeno município com economia agrícola atende as necessidades básicas da sua população, em específico a de origem rural. Os homens foram os habitantes do campo que mais se deslocaram, tanto para o centro urbano do município, como para outros pequenos municípios vizinhos. Mas, isto se dava sobretudo, porque eram eles que usavam os meios de transporte próprios. Já as mulheres apresentaram o deslocamento circunscrito ao distrito do município em função do menor poder de consumo e da falta de transporte próprio, o que limitava a mobilidade para fora de seus espaços de origem.

\section{REFERÊNCIAS}

ALVES, L. A.; SILVA, A. R. P. "Desafios e potencialidades das pequenas cidades no contexto de uma sociedade urbana: alguns apontamentos com base na realidade de FrutalMG e São Gotardo-MG". Raega - O Espaço Geográfico em Análise, Curitiba, v. 35, p. 7-37, dez/2015. Disponível em: http://revistas.ufpr.br/raega/article/view/38065. Acesso em: 16 mar. 2016.

BAENINGER, R. Deslocamentos populacionais, urbanização e regionalização. Revista Brasileira de Estudos Populacionais, Brasília, v. 15, n.2, p. 67- 81, 1998. Disponível em: https://www.rebep.org.br/revista/article/view/4 05. Acesso em: 12 ago. 2015

BAUMAN, Z. Modernidade Líquida. Rio de Janeiro: Jorge Zahar Editor, 2001.

BELL, D; JAYNE, M. Small Cities? Towards a Research Agenda. International Journal of Urban and Regional Research. v. 33, p. 683-689, 2009.
BOLFARINE, H.; BUSSAB, W.O. Elementos de Amostragem. São Paulo: Edgar Blucher, 2005.

CANDIDO, Antônio. Os parceiros do Rio Bonito: estudo sobre o caipira paulista e a transformação dos seus meios de vida. 11a ed. Rio de Janeiro: Ouro sobre Azul, 2010.

CASARIL, C.C.; SAMPAIO, F. S. "A inserção da cidade pequena de Ampére - PR na rede urbana a partir da dinâmica industrial". Raega - O Espaço Geográfico em Análise, Curitiba, v. 37, p. 227-54, 2016. Disponível em: http://revistas.ufpr.br/raega/article/view/41683. Acesso em: 14 nov. 2016.

COLUCCI, D. G.; SOUTO, M. M. M. Espacialidades e territorialidades: conceituação e exemplificações. Geografias (UFMG), v. 7, n. 1, p. $114 \quad-127,2011 . \quad$ Disponível em:http://www.igc.ufmg.br/portaldeperiodicos/i ndex.php/geografias/article/view/540/411.

Acesso em: 03 mar. 2013.

CORRÊA, R. L. Globalização e Reestruturação da Rede Urbana - Uma Nota sobre as Pequenas Cidades. Revista Território, Rio de Janeiro, ano IV, no 6, jan./jun., p.43-53, 1999. Disponível em: http://www.revistaterritorio.com.br/pdf/06_5_c orrea.pdf. Acesso em: 9 jul. 2012.

ENDLICH, A. M. Pensando os papéis e significados das pequenas cidades do Noroeste do Paraná. Presidente Prudente: UNESP, 2006.

FRESCA, T. M. Centros locais e pequenas cidades: diferenças necessárias. Mercator, Fortaleza, vol. 9, n. 20, 2010.

GIL, A. C. Como elaborar projetos de pesquisa. São Paulo: Atlas, 2010.

IBGE. Sítio oficial do Instituto Brasileiro de Geografia e Estatística. Disponível em: http://www.ibge.gov.br.

IBGE. Classificação e caracterização dos espaços rurais e urbanos do Brasil: uma primeira aproximação / IBGE, Coordenação de Geografia. - Rio de Janeiro: IBGE, 2017. 


\section{OS RURAIS E A CIDADE: A MOBILIDADE SOCIOESPACIAL DOS HABITANTES DO CAMPO EM PEQUENOS MUNICÍPIOS DE ECONOMIA AGRÍCOLA}

JUNIOR, O. M. As cidades pequenas na Geografia brasileira: a construção de uma agenda de pesquisa. GEOUSP: Espaço e Tempo, São Paulo, n. 35, p. 19-33, 2013.

MAIA, D. S. Cidades Médias e Pequenas do Nordeste: Conferência De Abertura. IN: LOPES, D. M.F.; HENRIQUE, W. CIDADES MÉDIAS E PEQUENAS: TEORIAS, CONCEITOS E ESTUDOS DE CASO. SALVADOR, SEI, 2010. 250 p.

MARENGO, S. N.; RAINER, B. F. Abordagens teóricas e metodológicas para pensar as cidades pequenas: alguns apontamentos. Simpósio Cidades Médias e Pequenas da Bahia. 2014. Anais... 2014, 15p.

MATOS, R.; BAENINGER, R. Migração e urbanização no Brasil: processos de concentração e desconcentração espacial e o debate recente. Cadernos do Leste, Belo Horizonte, IGC/UFMG, v. 6, n. 6, p. 7-44, 2004.

MATOS, R. Das grandes divisões do Brasil à ideia do urbano em rede tripartite. En R. Matos (Org). Espacialidades em rede: população, urbanização e migração no Brasil contemporâneo. Belo Horizonte: C/Arte, 2005.

PEREIRA, S. R. MOBILIDADE ESPACIAL E ACESSIBILIDADE À CIDADE. OKARA: Geografia em debate, João Pessoa, v.1, n.1, p. 43-76, 2007. Disponível em: http://www.okara.ufpb.br/ojs2/index.php/okara/ article/view/1246 Acesso em: 13 set. 2014.

REICHARDT CS \& COOK TD. Beyond qualitative versus quantitative methods. In TD Cook \& LS Reichardt (orgs.). Qualitative and Quantitative Methods in Evaluation Research. Sage, Londres, p. 7-30, 1979.
SANTOS, M. Espaço e Sociedade. Rio de Janeiro: Vozes, 1979a.

O espaço dividido: os dois circuitos da economia urbana dos países subdesenvolvidos. Rio de Janeiro: Francisco Alves, 1979b.

A Urbanização brasileira. São Paulo: Hucitec, 1993.

SILVEIRA, T. V. O papel das pequenas cidades na rede urbana: um estudo acerca do desenvolvimento da microrregião de Viçosa-MG.

Viçosa, 2014. 98f. Dissertação (Mestrado em Arquitetura e Urbanismo) - Programa de Pós Graduação em Arquitetura e Urbanismo, Universidade Federal de Viçosa - UFV, Viçosa, 2014.

VASCONCELLOS, Eduardo Alcântara. Transporte urbano, espaço e equidade: análise das políticas públicas. São Paulo: Annablume, 2001.

VEIGA, J. E. A dimensão rural do Brasil. Estudos Sociedade e Agricultura, São Paulo, n. 22, p. 7194, abril, 2004. Disponível em: http://r1.ufrrj.br/esa/V2/ojs/index.php/esa/articl e/view/246. Acesso em: 19 abr. 2013.

WAGNER, D; ASSIS, W, S de. Conexões entre campo e cidade na Amazônia paraense: agricultores familiares e suas relações com a cidade de Marabá- PA. Revista Extensão Rural, Santa Maria, v. 21, n.2, abri-jun de 2014. Disponível em: https://periodicos.ufsm.br/extensaorural/article/ view/8932. Acesso em: 21 out. 2014. 